\title{
Smart gold nanoparticles enhance killing effect on cancer cells
}

\author{
$\mathrm{KUN} \mathrm{SONG}^{1 *}$, PENG XU $^{2 *}$, YONGDE MENG ${ }^{2}, \mathrm{FENG} \mathrm{GENG}^{1}, \mathrm{JIE} \mathrm{LI}^{1}$, \\ ZHAO LI ${ }^{1}$, JAMES XING $^{4}$, JIE CHEN ${ }^{2,3}$ and BEIHUA KONG ${ }^{1}$ \\ ${ }^{1}$ Department of Obstetrics and Gynecology/Gynecological Cancer Laboratory, Qilu Hospital of \\ Shandong University, Ji'nan, Shandong, P.R. China; ${ }^{2}$ Department of Biomedical Engineering, University of Alberta; \\ ${ }^{3}$ National Research Council/National Institute of Nanotechnology; ${ }^{4}$ Cross Cancer Institute, Edmonton, AB, Canada
}

Received August 18, 2012; Accepted October 11, 2012

DOI: 10.3892/ijo.2012.1721

\begin{abstract}
The present study explored the cellular uptake dynamics, the subcellular location and the internalization mechanisms of gold nanoparticles (GNPs) and glucose-capped GNPs (Glu-GNPs). The cancer radiotherapy-enhancing effects of GNPs were also evaluated. We synthesized the GNPs and Glu-GNPs by the seeding technique. The effects on cellular uptake and the radiosensitizing effect induced by GNPs and Glu-GNPs at lower doses were investigated using two human cancer cell lines (HeLa and MCF-7). The intracellular location of the nanoparticles was analyzed by transmission electron microscopy (TEM). Analysis of cellular apoptosis following GNP-based radiotherapy was performed by flow cytometry and TUNEL assay. Cancer cells took up more Glu-GNPs than naked GNPs and the uptake curve showed size- and celldependent uptake. GNPs were mainly located in the cytoplasm and endocytosis is the mechanism behind the internalization of GNPs and Glu-GNPs. Lower doses of GNPs and Glu-GNPs still enhanced the killing effect using X-ray irradiation, although the apoptotic rate was not altered. The results presented in this study provide evidence that Glu-GNPs may have a bright future in tumor-targeted diagnosis and treatment.
\end{abstract}

\section{Introduction}

Worldwide, malignant tumors are the leading cause of human mortality (1). In order to successfully treat cancer, it is crucial

Correspondence to: Dr Jie Chen, Department of Biomedical Engineering, University of Alberta, 116 St. and 85 Ave., Edmonton, AB T6G 2R3, Canada

Email: jc65@ualbeta.ca

Dr Beihua Kong, Department of Obstetrics and Gynecology, Qilu Hospital of Shandong University, 107 Wenhuaxi Road, Ji'nan 250012, Shandong, P.R. China

E-mail: kongbeihua@yahoo.com.cn

${ }^{*}$ Contributed equally

Key words: gold nanoparticles, glucose-capped gold nanoparticles, tumor targeting, cancer, radiotherapy to increase the cytotoxicity on targeted tumor cells while reducing side-effects on normal cells during radiotherapy. Nanotechnology combined with biomedical techniques offers us tremendous opportunities and challenges to develop improved cancer diagnosis and therapeutic designs (2-4). An ideal strategy is to develop effective nanoscale radiosensitizers specifically targeting tumor cells. For instance, naked gold nanoparticles (GNPs) can accumulate at tumor tissues based on passively targeting mechanisms and experimental studies have shown promising results for the use of GNPs as effective radiosensitizers (5).

The size of nanoparticles used in cancer treatment should be large enough to prevent their rapid leakage from tumor tissue into blood capillaries. On the other hand, the size should also be small enough to avoid capture by macrophages in the reticuloendothelial system (RES). The optimized size of nanoparticles used in cancer treatment is suggested to be $\sim 50-100 \mathrm{~nm}$ to accumulate on tumor tissues utilizing so-called 'enhanced permeability and retention' (EPR) effect (6). Sperling et al systematically and analytically reviewed the biological applications of GNPs recently. However, the majority of biological research has involved small-sized GNPs (5-20 nm) (7), which are easily prepared, but are too small to take advantage of the EPR effect in vivo to target tumors. The mechanism of cellular uptake of GNPs of large sizes ( $(14-100 \mathrm{~nm})$ has previously been reported $(8,9)$. However, the intracellular uptake dynamics and the biological effects of these large-sized GNPs, in particular functionalized GNPs such as glucose-capped GNPs (Glu-GNPs), have never been studied in depth. Furthermore, the dose of GNPs used in published studies is high ( 100-10,000 billion particles per ml) (10-13), which may induce severe side-effects and limit its clinical applications. Our aim in this study was to systematically investigate the minimum effective dose of GNPs, which is critical for clinical trials.

Although naked GNPs can accumulate at tumor tissues by passive targeting mechanisms, GNPs conjugated with tumorspecific ligands can achieve active targeting at tumor lesions, which is more promising for tumor diagnosis and treatment. In our previous study, we repored on the binding of GNPs with glucose for targeted delivery (12). The size of GNPs used was $10.8 \mathrm{~nm}$. In this study, we investigated the impact of different sized GNPs on cell uptake and distribution. We synthesized the GNPs with larger sizes ( 57 and $84 \mathrm{~nm}$ ) by a new method based 
on a modified seeding technique. The potential effects on tumor cellular uptake and the radiosensitizing effect induced by these large-sized glucose-capped GNPs (Glu-GNPs) at lower doses were investigated using two human cancer cell lines ( $\mathrm{HeLa}$ and MCF-7). We systemically investigated the cellular uptake dynamics, the subcellular location and the internalization mechanisms of Glu-GNPs. The cancer radiotherapy-enhancing effects of GNPs were also evaluated.

\section{Materials and methods}

Cell lines and cell growth curve. The HeLa human cervical cancer cell line and the MCF-7 human breast cancer cell line were purchased from The American Type Culture Collection (ATCC). Cells were cultured in DMEM medium (Gibco Life Technologies) enriched with $10 \%$ heat-inactivated fetal bovine serum (FBS; Gibco) plus $100 \mathrm{IU}$ penicillin G, and $100 \mathrm{mg} / \mathrm{ml}$ streptomycin (Sigma), and incubated under standardized conditions $\left(37^{\circ} \mathrm{C}, 5 \%\right.$ carbon dioxide, $100 \%$ humidity).

Cells $\left(10 \times 10^{4}\right.$ per dish) were seeded and the cells kept growing for seven days under the same conditions. MTT assay was used to determine the cell growth based on the optical density (OD) value of the cells in each dish every day. MTT assay was applied as described previously with slight modifications (14). Briefly, following the procedures mentioned above, $200 \mu \mathrm{l}$ of the MTT dye $(5 \mathrm{mg} / \mathrm{ml})$ were added into each dish. Three hours later, the unreactive supernatants in each dish were carefully aspirated and were replaced with another $1 \mathrm{ml}$ of dimethyl sulfoxide (DMSO) solution to dissolve the reactive dye. Subsequently, $200 \mu 1$ solution in each dish was then removed into a well in a 96 -well plate. The OD value of each cell sample at $490 \mathrm{~nm}$ was read using an automatic multiwell spectrophotometer (Bio-Rad-Coda, Richmond, CA). The negative control well, which contained medium only, was used to set the absorbance to zero. The experiments were performed in triplicate and the averaged values were used to draw the growth curves for both HeLa and MCF-7 lines.

\section{Synthesis and characteristics of GNPs and Glu-GNPs}

Synthesis procedure for GNPs of various sizes. We synthesized the GNPs with a modified protocol based on our previous study (12). In brief, the mixture of $25 \mathrm{ml}$ deionized (D.I.) water and $0.5 \mathrm{ml}$ aqueous solution of $\mathrm{HAuCl}_{4}(25 \mathrm{mM})$ was heated in an oil bath at $\sim 120-140^{\circ} \mathrm{C}$ with stirring speed at $300 \mathrm{rpm}$. After reflux for $10 \mathrm{~min}, 2.5 \mathrm{ml}$ aqueous solution of sodium citrate $(34 \mathrm{mmol} / \mathrm{l})$ was quickly added into the reflux system. After continuous reflux for another $10 \mathrm{~min}$ and cooling to room temperature, GNPs with an average diameter of $21 \mathrm{~nm}$ were obtained, which were used as seeds for the preparation of larger-sized GNPs.

The mixture of D.I. water $(25 \mathrm{ml})$, sodium citrate solution (34 mM, $0.5 \mathrm{ml})$ and the seed GNPs $(2 \mathrm{ml})$ was heated in an oil bath at $\sim 120-140^{\circ} \mathrm{C}$ with the stirring speed at $300 \mathrm{rpm}$. After a 10 -min reflux, $0.5 \mathrm{ml} \mathrm{HAuCl}_{4}(25 \mathrm{mM})$ was quickly added into the reflux solution, followed by continuous reflux for another $10 \mathrm{~min}$ and then cooling to room temperature. In this case, GNPs with an average diameter of $\sim 57 \mathrm{~nm}$ were obtained. Alternatively, $1 \mathrm{ml}$ of $21-\mathrm{nm}$ GNP seeds was added to the mixture reaction system mentioned above and then GNPs with an average diameter of $84 \mathrm{~nm}$ were obtained. We functionalized the naked GNPs by adding $4 \mathrm{ml}$ of $25 \mathrm{mM}$ thioglucose into the previously prepared GNP solutions and then mixed them at room temperature for $24 \mathrm{~h}$ to obtain Glu-GNPs. Both naked GNPs and Glu-GNPs were dialyzed for $48 \mathrm{~h}$ and sterilized using $200 \mu \mathrm{m}$ aperture filter before use. The schematic diagram of the procedure for synthesizing GNPs and Glu-GNPs is shown in Fig. 1.

The sizes and shapes of the prepared nanoparticles were measured by transmission electron microscopy (TEM). To obtain the size distribution of nanoparticles, we used the PerkinElmer Lambda 900 spectrometer (PerkinElmer, Santa Clara, CA) to scan the visible absorption spectra within a $200-800 \mathrm{~nm}$ range of both freshly prepared GNP and Glu-GNP stock solutions. Inductively, coupled plasma mass spectrometry (ICP-Mass; Elan 6000, Perkin Elmer) was used to measure the final concentrations of the GNP solutions with different sizes. The surface characterization of Glu-GNPs was carried out using X-ray photoelectron spectroscopy (XPS) to determine the elemental composition on each Glu-GNP. Both ICP-Mass and XPS mass measurements were repeated three times for each sample.

Intracellular distribution of nanoparticles. To investigate the dynamic intracellular distribution of GNPs and Glu-GNPs, $6 \times 10^{5}$ cells were seeded in each culture dish and allowed to adhere and acclimate for one day. GNPs and Glu-GNPs of different sizes (57 and $84 \mathrm{~nm}$ ) were then applied to the cells with the final concentration of $7 \times 10^{8}$ particles $/ \mathrm{ml}$ and incubated with the cells for different periods of time (1, 6 and $24 \mathrm{~h})$ at $37^{\circ} \mathrm{C}$. Following two washes with phosphate-buffered saline (PBS), cells were collected and fixed with cold $2 \%$ glutaraldehyde in $0.1 \mathrm{M}$ sodium cacodylate buffer at $4^{\circ} \mathrm{C}$ for at least $4 \mathrm{~h}$. The cells were post-fixed in $1 \%$ osmium tetroxide in $0.2 \mathrm{M}$ sodium cacodylate buffer for $1 \mathrm{~h}$ and then stained with $2 \%$ aqueous uranyl acelate for $30 \mathrm{~min}$ at room temperature, followed by dehydration in a graded series of ethanol. Propylene oxide was used as a link reagent before embedding the cells in closed, labeled gelatine capsules with fresh resin. Ultrathin sections of the samples were cut and observed with a Philips/FEI (Morgagni) Transmission Electron Microscope with a CCD camera (TEM-CCD). The intracellular location of the GNPs and Glu-GNPs was then analyzed.

GNP and Glu-GNP uptake by cells. To dynamically investigate the difference between the cellular uptake of GNPs and that of Glu-GNPs, HeLa and MCF-7 cells were individually seeded in dishes $\left(6 \times 10^{5}\right.$ cells per dish) and cultured overnight. Either GNPs or Glu-GNPs with sizes of $57 \mathrm{~nm}$ were added into the cell cultures to reach the final concentration of $2.5 \times 10^{9}$ particles $/ \mathrm{ml}$ and incubated with the cells for different periods of time (15 and $30 \mathrm{~min}, 1,3,6,12,24$ and $48 \mathrm{~h}$ ) at $37^{\circ} \mathrm{C}$. The medium with free nanoparticles was removed and the cells were washed with PBS twice at each time-point. Cells were collected and the number of cells was counted, followed by centrifugation. A total of $4 \mathrm{ml}$ of $20 \% \mathrm{HNO}_{3}$ was then added into each sample to lyse the pellets. The gold mass in the lysis solution was detected by ICP-Mass. We calculated the number of nanoparticles via the measurement of gold in the solution. In addition, the number of GNPs and Glu-GNPs in the lysis solution divided by the number of cells provided a 


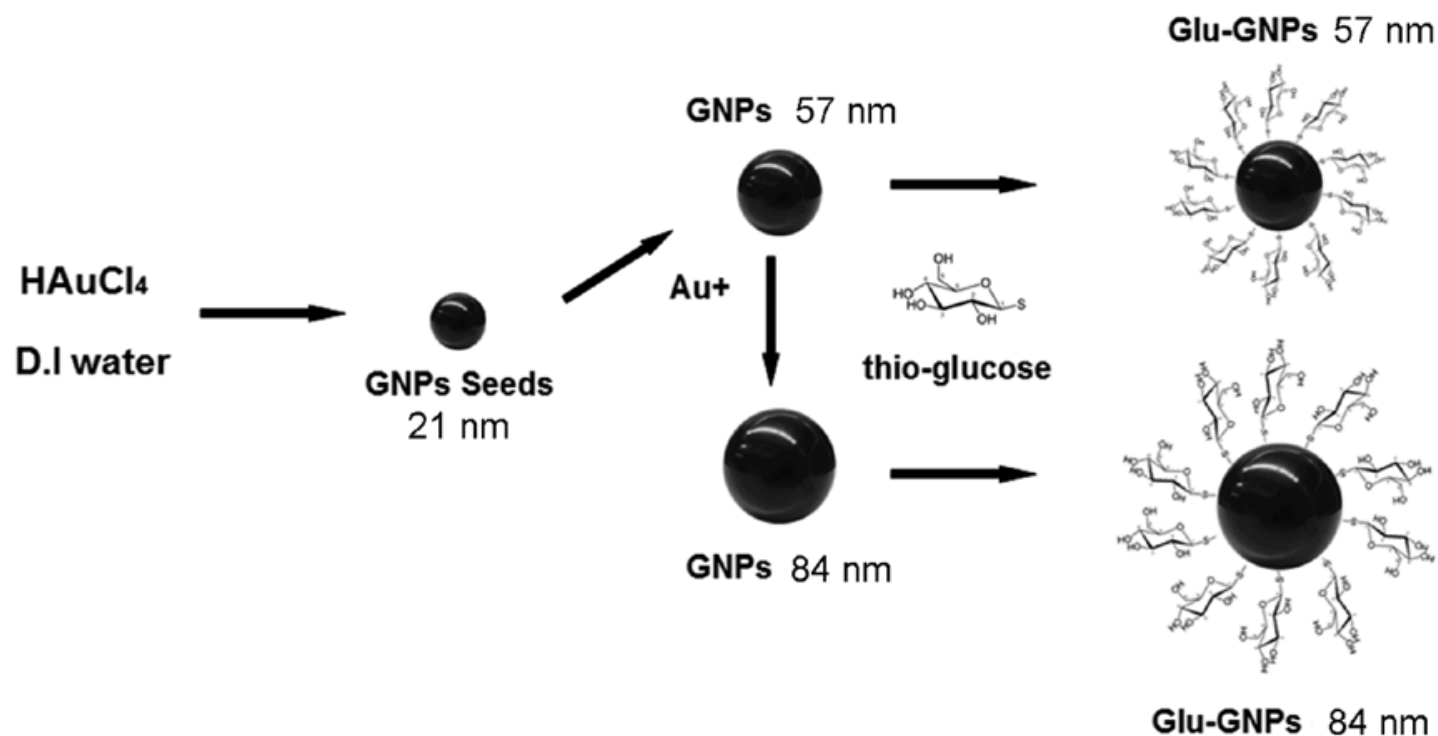

Figure 1. Schematic diagram of the procedure for synthesizing GNPs and Glu-GNPs.

quantitative measurement of GNPs uptaken in each cell. Each experiment was performed in triplicate, and the average values and standard deviation are presented. The same experiments were performed for the 84-nm nanoparticles.

Determination of cell death. MTT assay was used to determine cell death induced by optimal X-ray doses and time-points in the following experiments. Irradiation was carried out at various $\mathrm{X}$-ray doses $(5,10$ and $15 \mathrm{~Gy})$ and the cells were allowed to keep growing for 24, 48, 72, 96 and $120 \mathrm{~h}$. Based on the MTT results at each time-point (data not shown), the irradiation dose of $10 \mathrm{~Gy}$ and incubation time of $96 \mathrm{~h}$ after $\mathrm{X}$-ray treatment were selected for our cell death experiments.

Quantitative analysis of apoptosis or necrosis of the cells was performed by flow cytometry using the Annexin V-FITC apoptosis kit (BioVision, Milpitas, CA) as discribled previously (15). HeLa cells in $8 \mathrm{ml}$ of $10 \%$ FBS DMEM medium ( $2 \times 10^{5}$ cells/dish) were seeded and cultured overnight at $37^{\circ} \mathrm{C}$. The supernatants were removed and replaced with $8 \mathrm{ml}$ fresh glucose-free medium solution containing GNPs and Glu-GNPs $(57 \mathrm{~nm})$ with the final concentrations of 10 and $20 \mu \mathrm{M}$, respectively, in each well. After incubation for $48 \mathrm{~h}$, the medium containing the drugs was aspirated and the cells were rinsed with PBS twice and then replaced with another $8 \mathrm{ml}$ DMEM prior to X-ray radiation. Following irradiation, the cells were cultured for another $96 \mathrm{~h}$. Approximately $1 \times 10^{6}$ cells were collected, washed with PBS twice, and then suspended in $100 \mu \mathrm{l}$ of Annexin V binding buffer (1X) and incubated with $10 \mu \mathrm{l}$ Annexin $\mathrm{V}(20 \mu \mathrm{g} / \mathrm{ml})$ and $5 \mu \mathrm{l}$ propidium iodide (PI) for $15 \mathrm{~min}$ at room temperature in dark. A total of $400 \mu \mathrm{l}$ binding buffer were then added into each tube and the cells were analyzed with a FacsCalibur flow cytometer (Becton-Dickinison, Franklin Lakes, NJ) within $1 \mathrm{~h}$. Data analysis was performed with CellQuest software (Becton-Dickinison). Experiments were repeated six times. The results were interpreted as follows: cells that were Annexin V(-)/PI(-) (lower left quadrant) were considered as living cells, the Annexin V(+)/PI(-) cells (lower right quadrant) as apoptotic cells, Annexin V(+)/PI(+) (upper right quadrant) as necrotic or advanced apoptotic cells, and Annexin V(-)/PI(+) (upper left quadrant) as bare nuclei, or cells in late necrosis, or even cellular debris. Each sample including cells received treatment with both Annexin V and PI, blank cells received single staining with Annexin V alone or PI alone and non-stained cells were employed as references for setting up the parameters for flow cytometer detection.

TUNEL assay. TUNEL staining was used to identify the morphology features of cell death induced by either X-ray alone or irradiation plus GNPs. HeLa cells were seeded in cell culture dishes $\left(1 \times 10^{4}\right.$ cells per dish) and incubated overnight followed by the addition of either GNPs or Glu-GNPs. The final concentration of both GNPs was $20 \mathrm{mM}\left(2.5 \times 10^{9}\right.$ particles $\left./ \mathrm{ml}\right)$ and $10 \mu \mathrm{M}\left(1.25 \times 10^{9}\right.$ particles $\left./ \mathrm{ml}\right)$, respectively. After incubation for $48 \mathrm{~h}$, the cells were treated with X-ray irradiation (125 kVp with the Pantak Therapax 3 series) at a single dose of 10 Gy and were subsequently cultured for various periods of time (48, 72 and 96 h). At each time-point, TUNEL staining was performed following the instructions in the manual of the DeadEnd $^{\mathrm{TM}}$ Fluorometric TUNEL System (Promega Corp., Madison, WI) with slight modifications. In brief, cells were fixed in 4\% methanol-free formaldehyde in PBS for $30 \mathrm{~min}$ at room temperature. After washing with PBS twice, cells were permeabilized with $0.1 \%$ Triton X-100 solution for $5 \mathrm{~min}$ at $4^{\circ} \mathrm{C}$. The cells were washed twice and incubated with $100 \mu \mathrm{l}$ of the equilibration buffer at room temperature for $10 \mathrm{~min}$. The cells were then incubated with the TUNEL reaction mixture (Nucleotide Mix and rTdT) in a dark humidified chamber for $60 \mathrm{~min}$. The reaction was terminated with the kit $2 \mathrm{X}$ SSC reagent and the cells were washed with PBS twice to remove unincorporated fluorescein-12-dUTP. The slides were mounted in VECTASHIELD ${ }^{\circledR}$ mounting medium with DAPI (Vector Laboratories, Burlingame, CA) to stain the nuclei followed by the addition of coverslips to the slides and the edge of the coverslips was sealed by nail polish. The fluorescein-12-dUTPlabeled DNA of apoptotic nuclei appears green when visualized by a Zeiss LSM 510 Laser Scanning Confocal Microscope 


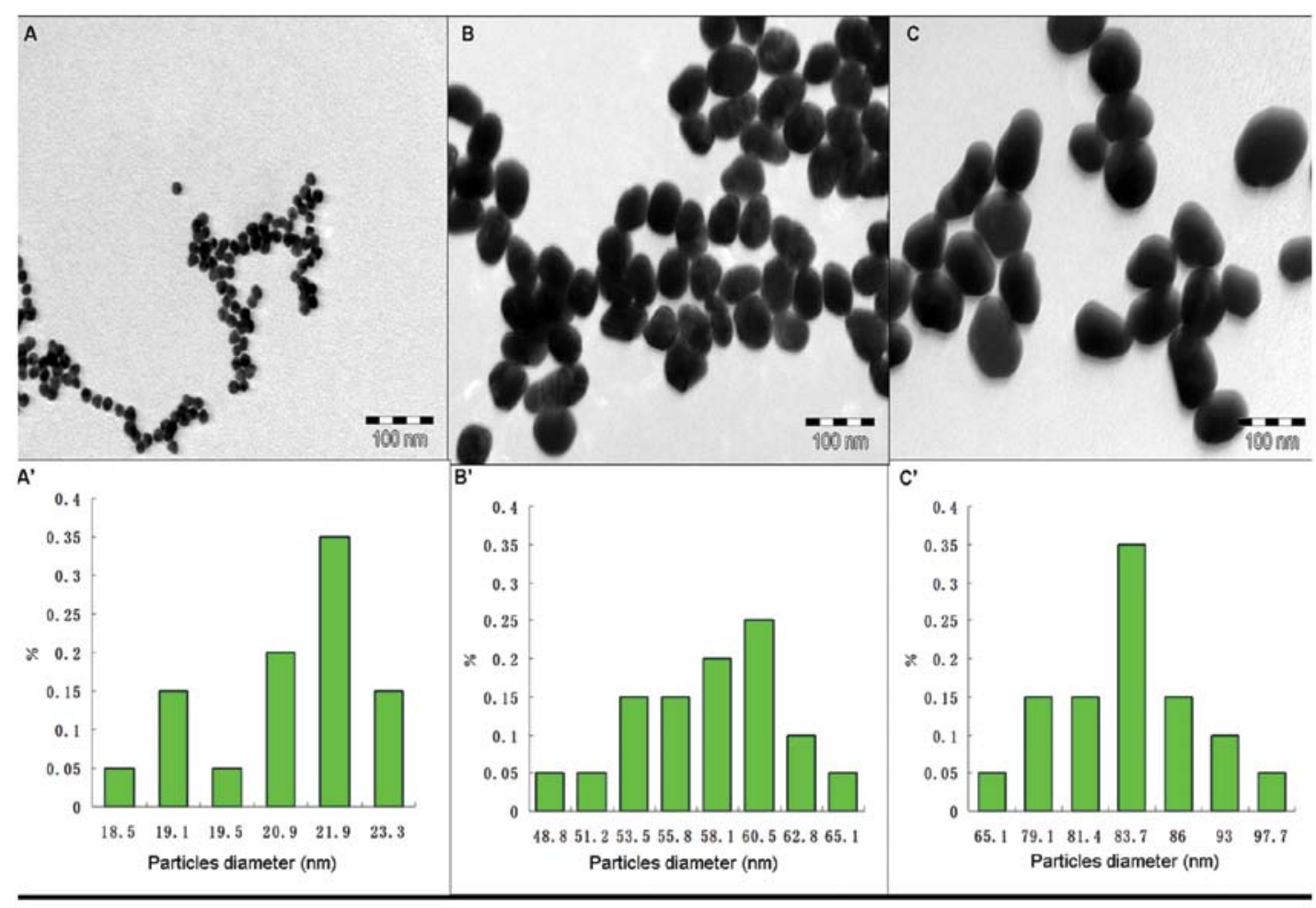

$21.20 \pm 1.47 \mathrm{~nm}$

$56.98 \pm 5.70 \mathrm{~nm}$

$83.71 \pm 10.50 \mathrm{~nm}$

Figure 2. Transmission electron microscopy (TEM) images of GNPs. (A, B and C) show the average diameters of the GNPs with a size of $21.20 \pm 1.47$ (the seeds), $56.98 \pm 5.7$ and $83.71 \pm 10.5 \mathrm{~nm}$, respectively.

(Zeiss, Germany). The cells without any interference and the cells with X-ray treatment only served as the controls.

Statistical analysis. The statistical analysis was performed using SPSS 14.0 for Windows. Differences between each group were analyzed by the Student's t-test. $\mathrm{P}<0.05$ was considered to indicate a statistically significant difference.

\section{Results}

Characteristics of GNPs. Fig. 2 shows the TEM images of different sized GNPs. Based on the TEM results, three sizes of GNPs with average diameters of $21.20 \pm 1.47 \mathrm{~nm}(\mathrm{~A})$, $56.98 \pm 5.7 \mathrm{~nm}(\mathrm{~B})$ and $83.71 \pm 10.5 \mathrm{~nm}(\mathrm{C})$, are presented. GNPs with a size of $21.20 \pm 1.47 \mathrm{~nm}$ served as the seeds. GNPs of 54 and $84 \mathrm{~nm}$ were obtained by letting gold molecules gradually grow on the surface of these seed GNPs in the reaction solutions until nanoparticles with the expected size was achieved. Using this seed method, we can easily prepare GNPs with uniform sizes and shapes. The sulfur-to-gold atom ratio was 1.02, 5.56 and 3.70 for 21, 57 and $84 \mathrm{~nm}$ Glu-GNPs, respectively. The results indicated that more thio-glucose molecules conjugated on the surface of the 57-nm GNPs particles. In other words, given the same amounts of glucose molecules, more Au atoms will be uptaken by the cells using 57-nm Glu-GNPs than the two other sized nanoparticles.

Distribution and internalization mechanisms of GNPs and Glu-GNPs in cells. More than 300 images were taken for this experiment. The distribution of GNPs and Glu-GNPs in the HeLa and MCF-7 cells was determined by TEM. Fig. 3 shows HeLa cells treated with either GNPs or Glu-GNPs $(57 \mathrm{~nm})$ at different incubation times (1, 6 and $24 \mathrm{~h})$. The GNPs were mainly located at the cytoplasm (Fig. 3B). However, several gold nanoparticles appeared in the area of the nucleus (Fig. 3F and G). More importantly, Fig. 3H shows the GNPs that were located inside the mitochondrion. These results regarding the detailed GNP location inside cells at the subcellular level have not been reported previously. GNPs and Glu-GNPs were rapidly internalized into the cells after the GNPs were added. TEM images showed that after $1 \mathrm{~h}$ of GNP administration, the GNPs reached areas around nucleus, while the cells continued to uptake GNPs. The distribution of GNPs and Glu-GNPs in the MCF-7 cells was the same as in the HeLa cells regardless of the sizes of the particles.

Fig. 3D shows a typical endosome containing two groups of GNPs near the cell membrane. The endosome is formed and moves inwards of the cell. The typical structure of the endosome then disappears, which suggests that a typical endocytosis procedure has occurred. Fig. 3C shows that the cell protrudes its pseudopodia to catch GNPs. All these images indicate that endocytosis is the mechanism behind the internalization of GNPs and Glu-GNPs.

Uptake of GNPs and Glu-GNPs by cells. The numbers of GNPs and Glu-GNPs uptaken by the HeLa and MCF-7 cells in cell lysates was quantified using ICP-Mass. Fig. 4 shows the growth curve of both HeLa and MCF-7 cells, which indicates 

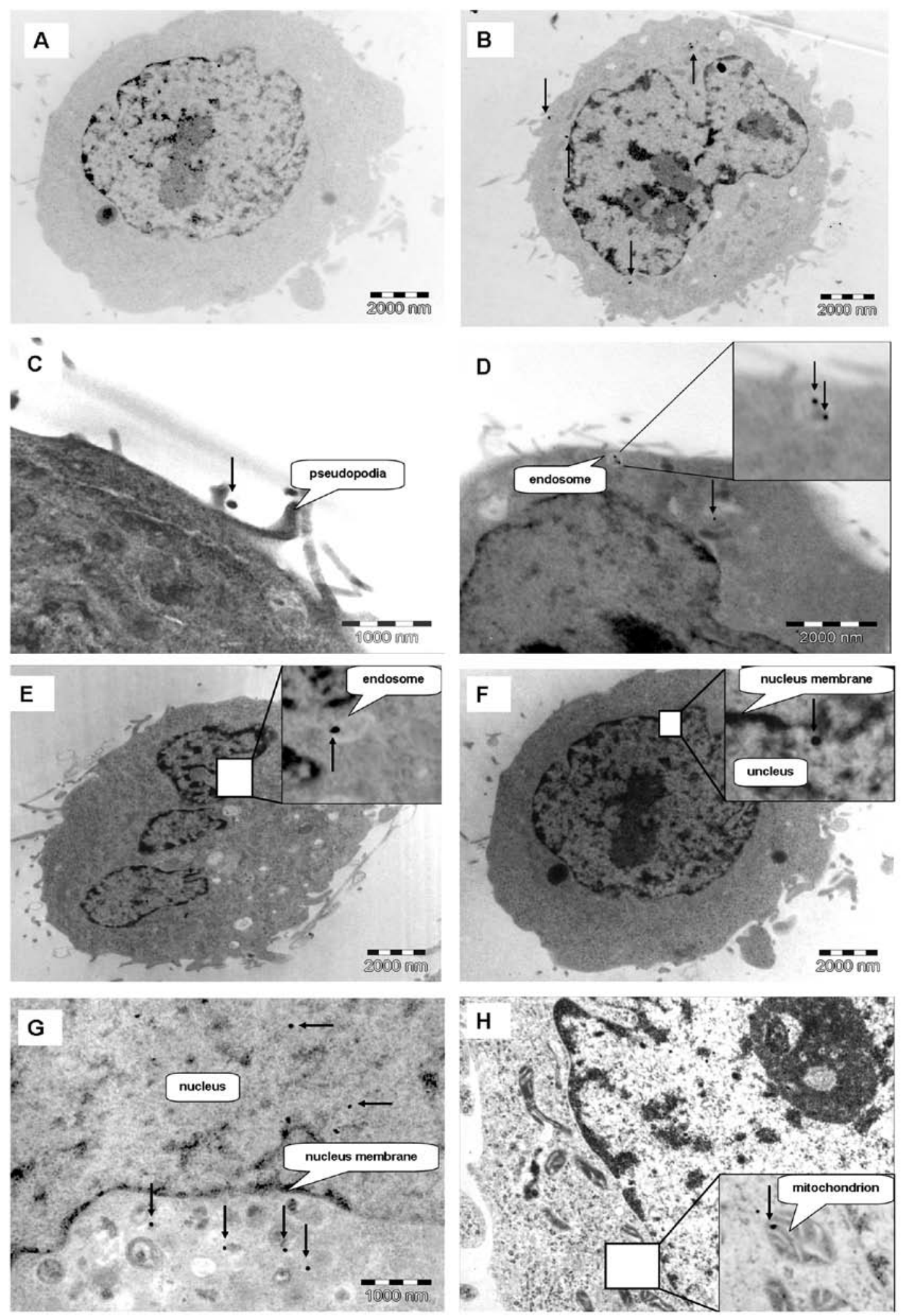

Figure 3. Distribution of GNPs and Glu-GNPs in HeLa and MCF-7 cells. (A) Control cells without nanoparticles. (B) Four groups of particles located inside the cytoplasm. (C) Formation of pseudopodia with nanoparticles in the centre. (D and E) Endosome containing nanoparticles. (F and G) Nanoparticles inside the nucleus. (H) One group of nanoparticles located inside the mitochondrion.

that the growth cycle is similar for both cells. However, HeLa cells grew much slower than the MCF-7 cells during the first five days. The average number of GNPs and Glu-GNPs in each cell is shown at Fig. 5, which confirms that both HeLa and MCF-7 cells took up more Glu-GNPs than GNPs. However,
MCF-7 cells took up more GNPs and Glu-GNPs than HeLa cells. MCF-7 cells reached the peak uptake value earlier than the HeLa cells (12 vs. 48 h).

The average number of size $57 \mathrm{~nm}$ nanoparticles within every $100 \mathrm{HeLa}$ cells was $8.71 \times 10^{3}$ for the naked GNPs and 


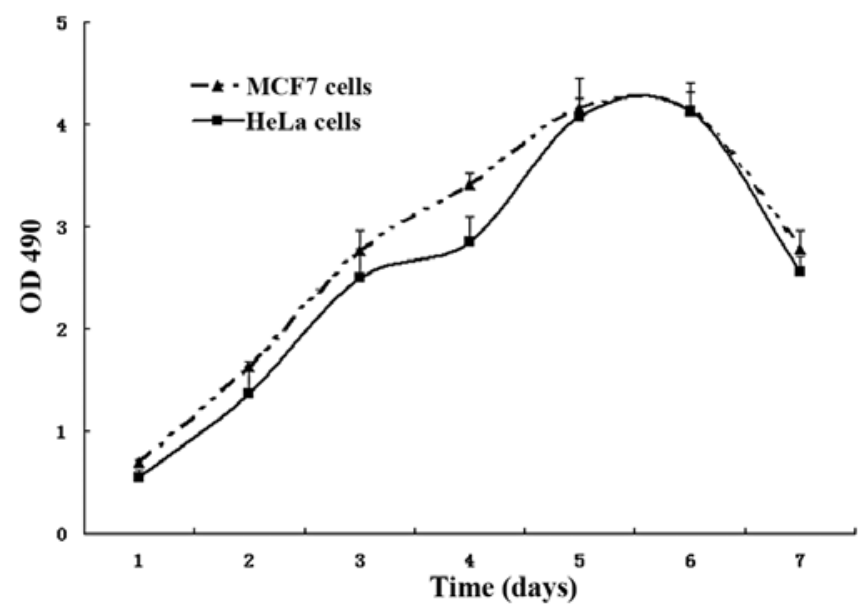

Figure 4. Growth curve demonstrating that HeLa cell grew slower than MCF-7 cells during the first five days.
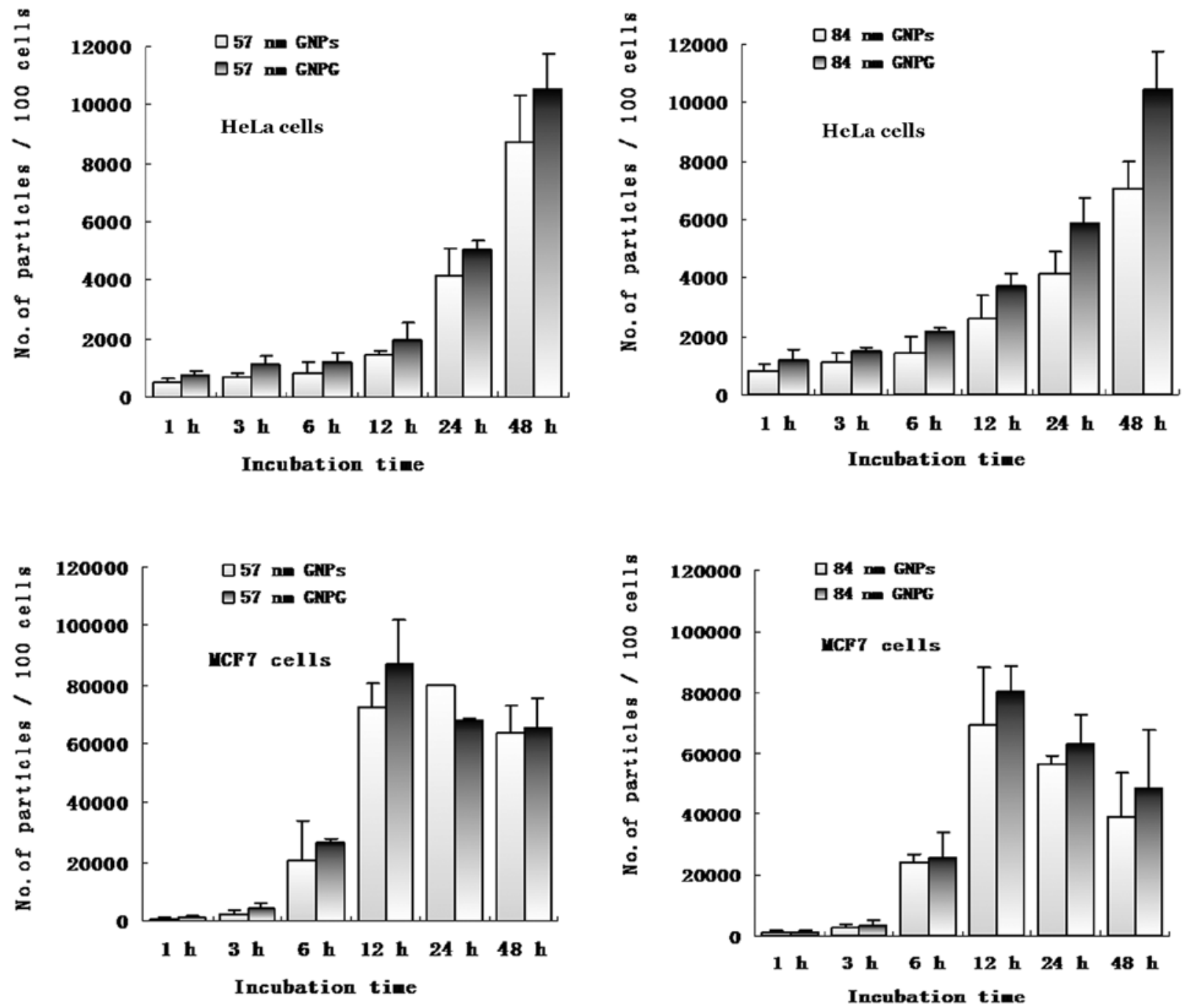

Figure 5. Uptake of GNPs and Glu-GNPs by HeLa and MCF-7 cells. The uptake of nanoparticles depends on the type of particles (GNPs vs. Glu-GNPs), the type of cells (HeLa cells vs. MCF-7 cells) and the size of the nanoparticles (57 nm vs. $84 \mathrm{~nm}$ ). The MCF-7 reached peak uptake much earlier than the HeLa cells. GNPG, GNP coated with glucose.

$10.51 \times 10^{3}$ for the Glu-GNPs after $48 \mathrm{~h}$ of incubation $(\mathrm{P}=0.043)$. Similarly, more Glu-GNPs were taken up by the cells than naked GNPs with a size of $84 \mathrm{~nm}$ after $48 \mathrm{~h}$ of incubation $\left(10.45 \times 10^{3}\right.$ vs. $\left.7.08 \times 10^{3}, \mathrm{P}=0.025\right)$ as shown in Table I. MCF-7 cells took up more naked GNPs $\left(6.34 \times 10^{4}\right.$ vs. $\left.8.71 \times 10^{3}, \mathrm{P}=0.034\right)$ with size a of $57 \mathrm{~nm}$ than the HeLa cells after $48 \mathrm{~h}$. 
Table I. The average number of nanoparticles uptaken by HeLa cells after $48 \mathrm{~h}$ of incubation.

\begin{tabular}{|c|c|c|}
\hline & \multicolumn{2}{|c|}{ Size } \\
\hline & $57 \mathrm{~nm}$ & $84 \mathrm{~nm}$ \\
\hline $\begin{array}{l}\text { The average number of } \\
\text { nanoparticles uptaken by } \\
100 \text { HeLa cells }\end{array}$ & $\begin{array}{c}8.71 \times 10^{3} \\
\text { Naked GNPs }\end{array}$ & $\begin{array}{c}7.08 \times 10^{3} \\
\text { Naked GNPs }\end{array}$ \\
\hline $\begin{array}{l}\text { The average number of } \\
\text { nanoparticles uptaken by } \\
100 \text { HeLa cells }\end{array}$ & $\begin{array}{c}1.051 \times 10^{4} \\
\text { Glu-GNPs }\end{array}$ & $\begin{array}{l}1.045 \times 10^{4} \\
\text { Glu-GNPs }\end{array}$ \\
\hline $\mathrm{P}$-value & 0.043 & 0.025 \\
\hline
\end{tabular}

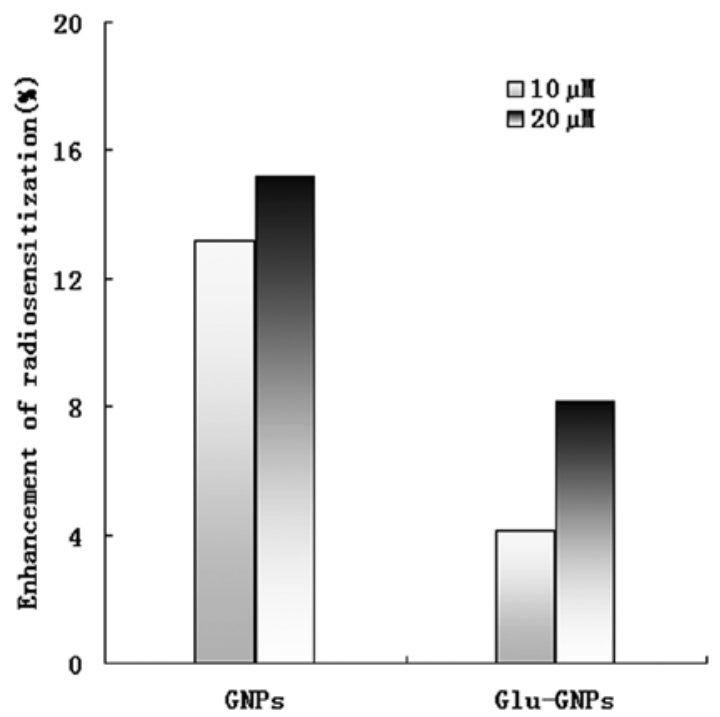

Figure 6. Enhancement of radiotoxic effects of GNP- and Glu-GNP-based $\mathrm{X}$-ray radiotherapy on HeLa cells.

Both the HeLa cells and MCF-7 cells took up more numbers of 57-nm GNPs/Glu-GNPs than 84-nm nanoparticles. For instance, more 57-nm Glu-GNPs were taken up than 84-nm Glu-GNPs by HeLa cells $\left(8.71 \times 10^{3}\right.$ vs. $\left.7.08 \times 10^{3}, \mathrm{P}=0.011\right)$, as well as by MCF-7 cells $\left(6.58 \times 10^{4}\right.$ vs. $\left.4.83 \times 10^{4}, \mathrm{P}=0.05\right)$ at $48 \mathrm{~h}$. Our results revealed that the uptake of nanoparticles was related to the surface characteristics of nanoparticles (GNPs vs. Glu-GNPs), the type of cells (HeLa vs. MCF-7), the size of nanoparticles (57 nm vs. $84 \mathrm{~nm}$ ) and incubation time. The size-dependent uptake result was in line with our expectations, that is Glu-GNPs components result in more glucose being conjugated on the surface of $57-\mathrm{nm}$ particles $(\mathrm{S} / \mathrm{Au}=10.71)$ than 84-nm particles $(\mathrm{S} / \mathrm{Au}=3.06)$. The time-point of the cell uptake peak is the optimal time for irradiation. Based on the results we obtained for the 57-nm GNPs and Glu-GNPs, the following experiments were designed. HeLa cells were used in our experiments as HeLa cells take up less nanoparticles than MCF-7 cells. If the treatment proved successful for HeLa cells, the same treatment would then be expected to be even more effective for MCF-7 cells.
GNP enhanced radiotherapy. To reduce the side-effects induced by GNPs and Glu-GNPs, lower nanoparticle doses (2.5x $10^{9} \mathrm{GNPs} / \mathrm{ml}, 20 \mu \mathrm{M}$ and $\left.1.25 \times 10^{9} \mathrm{GNPs} / \mathrm{ml}, 10 \mu \mathrm{M}\right)$ were used in our radiosensitivity study. The cells in left low quadrant are characterized by Annexin V(-)/PI(-), which represent live cells. While cells in the other three quadrants are dead cells. Both GNPs and Glu-GNPs can increase the death rate by X-rays in HeLa cells even at a lower dose. The relative radiosensitizing effect reached $15 \%$ when $20 \mu \mathrm{M}$ GNPs were used. However, the radiosensitizing effect of Glu-GNPs was not as effective as GNPs alone, $8 \%$ vs. $15 \%$ killing effects for $20 \mu \mathrm{M}$ and $4 \%$ vs. $13 \%$ killing effects for $10 \mu \mathrm{M}(\mathrm{P}=0.053)$ even though more Glu-GNPs than GNPs were uptaken by HeLa cells (please refer to our explanations in the Discussion) as shown in Fig. 6.

Apoptosis detection. The TUNEL method can be used to label the fragmented DNAs inside cells, which is a characteristic method for determining apoptosis. As shown in Fig. 7, X-rays clearly induced apoptosis compared to the blank controls. The size of TUNEL-positive nuclei tended to increase as incubation time increased (48, 72 and $96 \mathrm{~h}$ ) after X-ray treatment. There was no significant difference among cells only treated with X-ray alone or nanoparticles without X-ray irradiation. The results are in line with our flow cytometry analysis results.

Dual staining of cells with Annexin V and PI can be used to quantitatively distinguish apoptotic from necrotic cells. The apoptotic rate of the X-ray-treated group was significantly higher than the blank control $(7.75 \pm 1.51$ vs. $1.31 \pm .27 \%$, $\mathrm{P}=0.004)$. Compared to the cells treated with $\mathrm{X}$-ray alone, the cells that received GNPs or Glu-GNPs plus X-ray treatment showed no significant difference on apoptosis induction. As shown in Fig. 8, the apoptotic rate in the X-ray alone group was slightly higher than in the other groups, but with no significant statistical difference $(7.75 \pm 1.51$ vs. $6.70 \pm 0.78$ and $6.79 \pm 0.95$ vs. $7.46 \pm 1.31$ vs. $7.07 \pm 1.74 \%, \mathrm{P}>0.05)$.

\section{Discussion}

GNPs are promising novel nanoscale drug carriers, radiosensitizers and bio-imaging contractors for cancer diagnosis and therapy. The biological functions of GNPs have been extensively investigated in various types of malignant tumor. All the applications are based on the active chemistry and physical properties of gold atoms and the size-dependent passive tumor targeting mechanism of GNPs (16-19). Nanoparticles can selectively accumulate on tumor tissues due to their small sizes and the defective tumor vasculature. The diameter of the endothelial gap junction around fenestrated capillaries in normal human tissues is $60-80 \mathrm{~nm}$ (20). However, the size of the gap junction between endothelial cells of the incomplete cancer vasculature may vary from 100-600 nm 21,22). As a result, nanoparticles with sizes of 50-100 $\mathrm{nm}$ have the ability to enter and accumulate around tumor tissue. The non-functioning developed lymphatic drainage system of cancer cannot recollect these nanoparticle back into blood circulation, which is so-called EPR effect. However, it is difficult to control the size and shape of large GNPs during synthesis. The majority of GNP studies thus far have used small-sized nanoparticles with diameters ranging from 1.8-30 $\mathrm{nm}$. To investigate the 


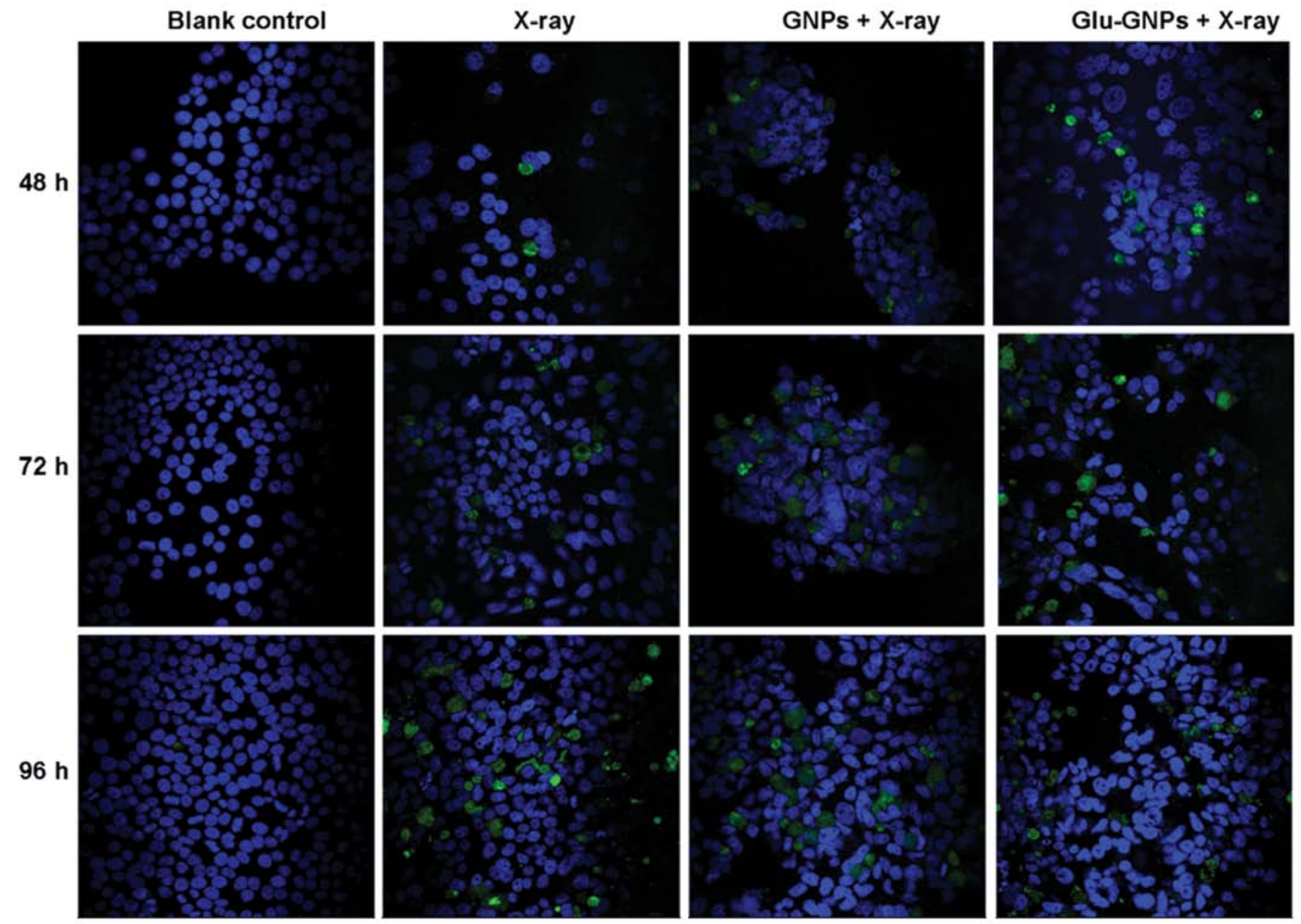

Figure 7. TUNEL staining following treatment with GNPs and Glu-GNPs plus X-ray irradiation in HeLa cells. Blue indicates the uncleus stained by PI. Green indicates TUNEL-positive cells, corresponding to apoptotic cells.

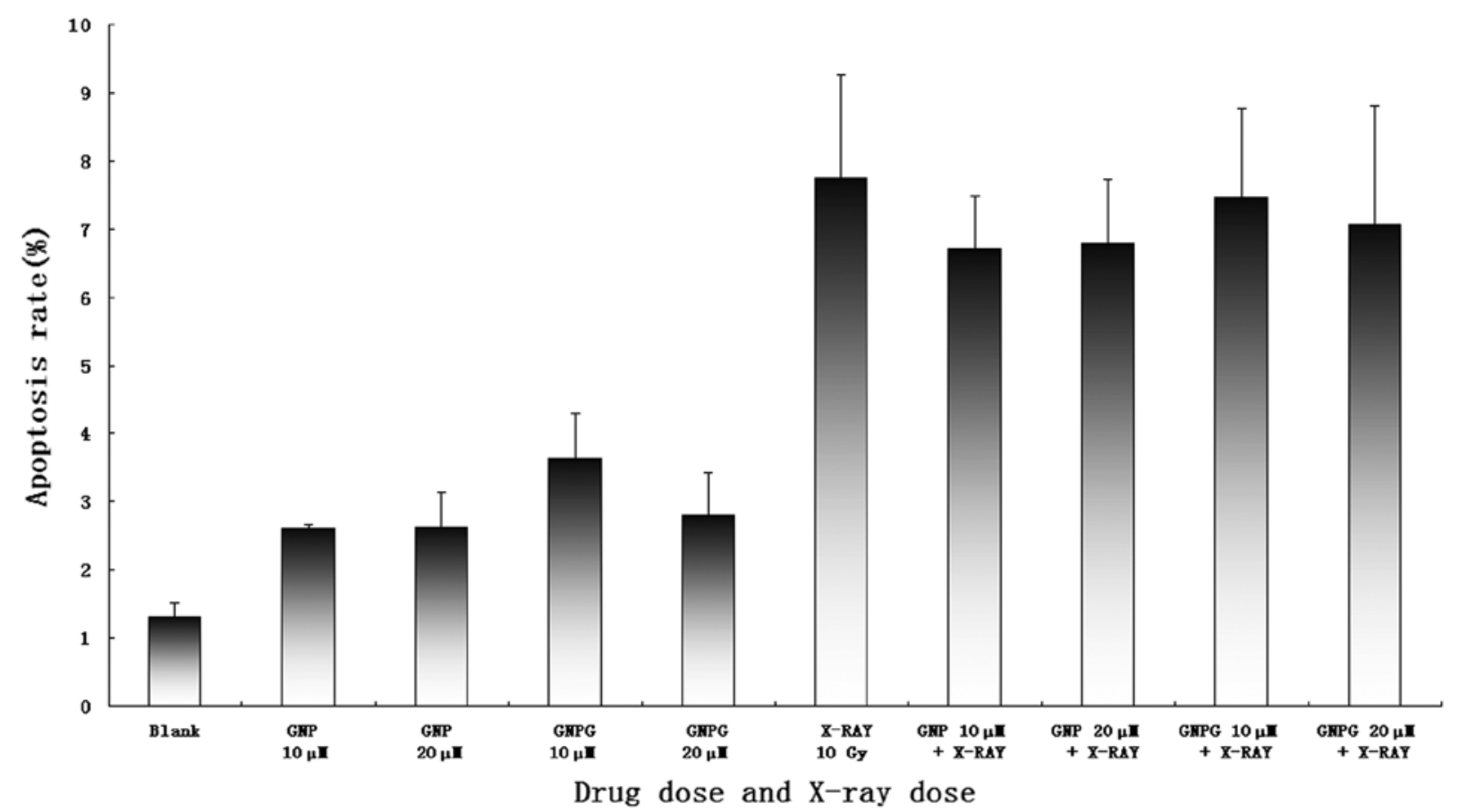

Figure 8. Comparison of apoptosis rate among HeLa cells treated with GNPs and Glu-GNPs followed by X-ray irradiation. GNPG, GNP coated with glucose. 
effect of larger-sized GNPs, we synthesized larger and high quality GNPs using a modified seeding technique based on the methods described in our previous study. Compared with a popular 'citrate reduction' method, our method can easily generate GNPs of a more uniform size and shape, which is important for assessing the GNP cytotoxic effects. TEM images confirmed that the size and shape of the resulting nanoparticles was uniform with an average diameter of 57 and $84 \mathrm{~nm}$.

Our XPS results revealed that many glucose molecules bound to the surface of GNPs. The ratio of the atom numbers for $\mathrm{S}$ to $\mathrm{Au}$ in a single 57 Glu-GNPs particle was 5.56, which was the highest among the three different sizes of nanoparticles we obtained. This suggests that, for glucose-coated GNPs, a single glucose molecule can carry more Au atoms into cells using a 57-nm nanoparticle; this type of nanoparticles is more cost-effective for treatment. The ICP-Mass results showed that, as the size increased, the nanoparticle concentration decreased accordingly, given the same mass concentration. The choice of optimal nanoparticle concentration is therefore essential as more nanoparticles mean more toxicity to the human body. Based on these observations and our uptake study results, more 57-nm nanoparticles were taken up by the cells. GNPs and Glu-GNPs with a size of 57-nm are desirable for future clinical studies.

There is an elevated glucose consumption and overexpression of glucose transporters (GLUTs) in cancers (23-25). It has long been recognized that cancer cells have increased rates of glucose metabolism compared with healthy cells. Gulcose can serve as an excellent tumor-targeting tracer. The most successful illustration of this theory is the widespread clinical application of PET scanning based on the selective uptake of $[18 \mathrm{~F}]$ fluorodeoxyglucose (FDG), a glucose analog that competes for glucose transport sites on the membrane by cancer cells (26). To target cancer cells more specifically, we modified the surface of naked GNPs using glucose so that active targeting to malignant tumor cells could be achieved. By doing so, a reasonably rapid enhancement of GNP uptake by both HeLa and MCF-7 carcinoma cell lines was clearly observed in our experiments by comparing the uptake of Glu-GNPs vs. naked GNPs. Therefore, when cancer cells uptake more glucose, more GNPs can also be internalized into the cells.

In this study, more 57-nm particles were taken up by the HeLa and MCF-7 cells than 84-nm nanoparticles regardless of whether glucose was capped on the GNPs or not. This result is partially in line with the results of the study by Chithrani et al, and the result confirms that $50 \mathrm{~nm}$ is the best choice for goldbased nanoparticles for tumor diagnosis and treatment $(8,9)$. However, we are the first group to illustrate that the Glu-GNP uptake by cells is also size-dependent and that the optimal size is $57 \mathrm{~nm}$ instead of $84 \mathrm{~nm}$. Based on our results, the nanoparticle size is critical for biomedical applications regardless of whether the surface of the nanoparticles is modified or not.

Another important factor for GNP-enhanced cell killing is when radiotherapy is applied after GNPs are administrated, and the application time depends on when the highest uptake is reached. Our results showed different cellular uptake dynamics for the HeLa cells and MCF-7 cells. The MCF-7 cells reached peak uptake much earlier than the HeLa cells (12 h vs. $48 \mathrm{~h}$ ) and more GNPs/Glu-GNPs were taken up by the MCF-7 cells than the HeLa cells (approximately a 10-fold increase).
Therefore, the best time to apply irradiation following the GNP application is $48 \mathrm{~h}$ for HeLa cells and $12 \mathrm{~h}$ for MCF-7 cells. The growth curve confirmed that the HeLa cells grew much slower than the MCF-7 cells at days two to four, when the GNPs and Glu-GNPs had just been administered to the cells. That may be one of the reasons why MCF-7 cells uptake more particles than HeLa cells. In conclusion, the uptake of gold-based nanoparticles depends on the surface characters of the nanoparticles, the size of the nanoparticles and the type of cells used. All the factors are important for the success of future clinical trials.

The mechanism of GNP-based radiosensitization is reported due to the generation of free radicals from gold atoms after they are bombarded by irradiation, such as X-ray. Free radicals can further generate reactive oxygen species (ROS) that are toxic and damage proteins and genetic materials $(27,28)$. However, the diffusion distance of free radicals is very short (29). For example, the diffusion range of ${ }^{1} \mathrm{O}_{2}$ is limited to approximately $10 \mathrm{~nm}$ in cells (30-32). Since the diameter of human cells ranges from approximately 10-100 $\mu \mathrm{m}$, the cancer killing effect depends on the site where the primary ${ }^{1} \mathrm{O}_{2}$ is generated. In other words, where the gold-based naoparticles locates consequently determines which subcellular structures are affected. Therefore, it is not surprising that the type of the response triggered by the activation of the GNPs depends on their intracellular localization. The subcellular location of nanoparticles is also essential for us to gain in-depth understanding of the toxic effect of GNPs on tumor cells. According to TEM images, we dynamically monitored the locations of both naked GNPs and Glu-GNPs in the HeLa and MCF-7 cells after 1, 6 and $24 \mathrm{~h}$. GNPs and Glu-GNPs were mainly located in the cell cytoplasms regardless of the cell type and incubation time. That means subcellular organelles nearby the nanoparticles inside cytoplasms are potential targets for gold-based $\mathrm{X}$-ray treatment. Fig. $3 \mathrm{H}$ shows that a group of nanoparticles is located in the mitochondrion; this is important as mitochondria-mediated apoptosis plays an essential role in cell death, which is one of the two apoptotic pathways in cells. Fig. 3F shows that several groups of nanoparticles inside the nucleus after a 24-h administration of 84-nm GNPs. Fig. 3G shows that a group of nanoparticles is located inside the nucleus close to the nuclear membrane after a 6-h administration of 84-nm GNPs. Although further evidence is required to support our discovery, it is reasonable to postulate that nanoparticles can enter the nucleus. The diameter of nuclear pore complexs (NPCs) is approximately 80-120 $\mathrm{nm}$. It has been reported that small nanoparticles are able to pass through the NPCs by passive diffusion. Larger particles are also able to pass through the large diameter of the pore, but at almost negligible rates (33). The detailed distribution of GNPs at subcellular organelles has not been reported previously. The majority of studies only describe the location in the cytoplasm. Chang et al recently confirmed the subcellular location of GNPs on the endoplasmic reticulum (ER) and Golgi apparatus using a double staining technique (11). Based on their results and ours, it is possible for GNPs to attach to the surface or even enter the subcellular organelles. The sucellular organelle-targeted radiotherapy using GNPs can thus be achieved.

Endocytosis has thus far been suggested to be the internalization mechanism for naked GNPs. Our TEM images clearly 


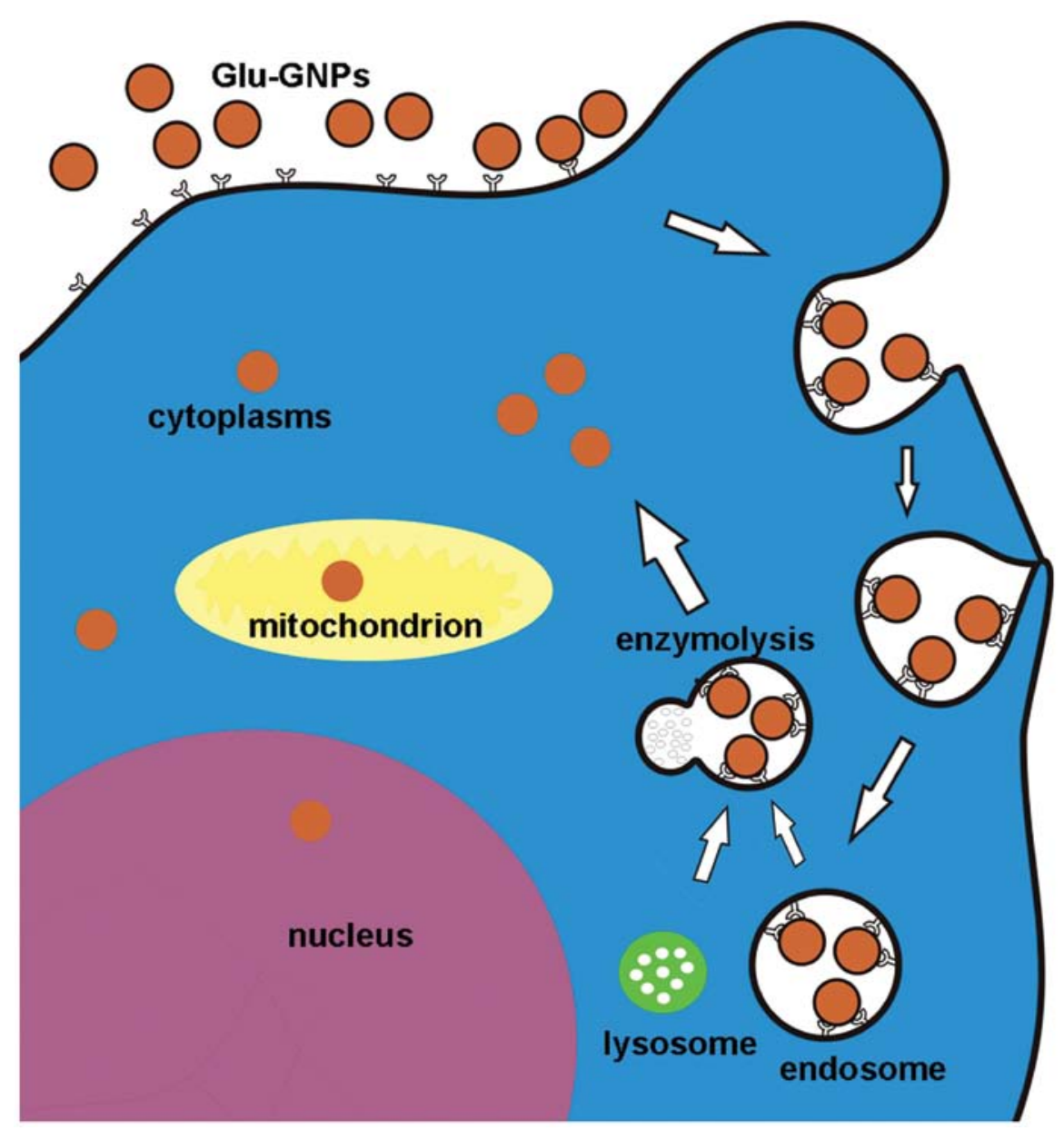

Figure 9. Schematic diagram demonstrating the hypothesis on Glu-GNP internalization. Shown is the receptor-mediated endocytosis procedure and the main locations of gold particles intracellularly.

showed that the endosome contained GNPs, which supports our cell endocytosis postulation. Chithrani et al $(8,9)$ demonstrated the receptor-mediated endocytosis process on three different cell lines by transferring coated GNPs. However, different ligands coated on the GNPs may lead to different results. However, how glucose-coated GNPs enter the cell has never been explored. Glucose can enter the cells by two ways. Facilitated diffusion and energy-dependent active transport are both mediated by GLUTs. With facilitated diffusion, GLUTs transport glucose molecules from higher to lower concentrations. Active transport occurs with glucose being carried into the cell against a concentration gradient (34). In order to determine the internalization mechanism of Glu-GNPs, two cancer cell lines with GLUT1 overpression were employed $(35,36)$. Both types of cells were first cultured in glucose-contained DMEM and then the medium was replaced with glucose-free medium, which means zero glucose concentration outside the cells. Subsequently, both the naked GNPs and Glu-GNPs were added into the medium. At various time-points, the uptake concentrations of the nanoparticles by the cells were measured by ICP-Mass. As mentioned above, more glucose-bounded GNPs than naked GNPs were taken by the cells. These results suggest that GLUTs play an important role in the uptake process. This process is an energy-dependent transport as the glucose concentration is lower in the medium. Six functional
GLUTs have been identified (GLUT 1-5,7) thus far. Among them, GLUT-1 is most important. With the highest glucose affinity, GLUT-1 can transport glucose molecules even in a lower concentration environment (37). Based on the results from our experiments and results from other reports, we can postulate that the procedure of Glu-GNP internalization is as follows: glucose molecules on the surface of GNPs first bind with GLUTs and then the endocytosis process is initiated (the size of GNPs is too large compared with the inner diameter of GLUT and thus impossible to directly pass through). The postulated schematic procedure for Glu-GNPs internalization and their subcellular location is shown in Fig. 9.

Combining nanotechnology and biology offers us tremendous opportunities to develop improved cancer diagnosis and therapeutic designs. However, there are also many challenges. Although nanoparticles can lead to biomedical breakthroughs, they may also cause toxic side-effects. The majority of studies have only focused on the positive effects of nanoparticles and have ignored their negative effects. Nanoparticles, in particular those made of undegradable non-biological components, can induce inflammation, affect immune reaction and cause platelet aggregation (38). GNPs are commonly considered safe for biomedical applications (39). However, the scientific evidence for the possible side-effects of GNPs is still lacking. One of the strategies is to limit the use of GNPs 
as much as possible before we completely understand the side-effects involved. In this study, the nanoparticle concentrations used were low, only $2.5 \times 10^{9}$ nanoparticles $/ \mathrm{ml}$ and $1.25 \times 10^{9}$ nanoparticles $/ \mathrm{ml}$, or the dose was much lower than the doses used in other reports. Our aim was to determine the minimal dose at which the GNP-radiosensitizing effects can be achieved. According to our MTT results, the dose of 10 Gy X-ray was the most effective and $96 \mathrm{~h}$ of incubation after irradiation was most effective based on our quantitative analysis results obtained from flow cytometry. At $96 \mathrm{~h}$ after radiotherapy, even at a low dose, GNPs and Glu-GNPs still led to enhanced irradiation cytotoxicity. The radiosensitivity reached $15 \%$ when $20 \mu \mathrm{M}$ GNPs were used. However, it should be noted that the radiosensitizing effect of the Glu-GNPs was not significantly different from that of the GNPs alone (15\% vs. 8\%, $\mathrm{P}=0.054)$, even though more Glu-GNPs were taken up by the HeLa cells. We postulated that radicals were generated when the external radiation source hit the GNPs or Glu-GNPs, which can induce cancer cell damage. When the surface of the GNPs was coated by glucose, this coated layer reduced the number of radicals coming out from the gold surface. On the other hand, evidence has shown a link between glucose metabolism and radiation resistance (40). Kunkel et al reported that the overexpression of GLUT-1 is also associated with cancer resistance to radiotherapy (41). These studies support the hypothesis that cellular glucose metabolism directly affects cellular radiosensitivity. In our study, the cells were exposed in glucose-free medium for $48 \mathrm{~h}$ after either naked GNPs or Glu-GNPs were added. The cells treated with naked GNPs did not uptake any glucose molecules under these conditions. However, the cells treated with glucose-capped GNPs still utilized the glucose attached on the surface of the GNPs. Therefore, the cells treated with naked GNPs should be more susceptible to X-rays. We also found in this study that the GNPs and Glu-GNPs had no effect on X-ray-induced apoptosis ( $\mathrm{P}>0.05)$. Generally, the type of cell death through necrosis and/or apoptosis depends on the drug property, the treatment conditions, the type of cells involved and the treatment dose (42). X-rays can induce cell death mainly by cell cycle arrest and partly by apoptosis (43). In this study, X-ray irradiation induced more apoptosis compared with the controls $(\mathrm{P}=0.004)$. However, TUNEL staining and flow cytometry confirmed that the apoptotic rate was not altered when the GNPs or Glu-GNPs were added. Chang et al (11) demonstrated that GNPs in conjunction with ionizing radiation significantly retarded tumor growth and induced apoptosis in B16F10 melanoma tumor-bearing mice; these results are not consistent with our results. Apoptosis is a complex procedure and many factors can affect its development. We used different cell lines and the dose of GNPs/ Glu-GNPs was relatively low in our in vitro experiments.

Based on our novel seeding techniques, we successfully developed high-quality GNPs and Glu-GNPs with larger sizes (57 and $84 \mathrm{~nm}$ ). Both types of gold-based nanoparticles were mainly located in the cytoplasm; however, some nanoparticles appeared inside the nucleus and on the surface of mitochondrion. This finding is original. The uptake curve of the GNPs and Glu-GNPs demonstrated a size- and cell-dependent uptake. TEM studies confirmed that endocytosis was the internalization mechanism of both GNPs and Glu-GNPs.
Due to glucose being bound to the surface of the GNPs, cancer cells took up more Glu-GNPs than naked GNPs through glucose receptor-mediated endocytosis, which is very useful for targeted delivery in vivo. Furthermore, lower doses of GNPs and Glu-GNPs can still enhance the killing effect using X-ray irradiation, although the apoptotic rate is not altered. The data given in our study may provide useful information as to the application of GNPs and their modified derivatives in clinical trials.

\section{Acknowledgements}

This study was supported by grants from the National Natural Science Foundation of China (nos. 81172488 and 30700897), the Doctor Foundation of Education Ministry (20090131120063) and the Canadian Breast Cancer Foundation.

\section{References}

1. American cancer society: Cancer Facts and Figures 2010

2. O'Neal DP, Hirsch LR, Halas NJ, Payne JD and West JL: Photothermal tumor ablation in mice using near infrared-absorbing nanoparticles. Cancer Lett 209: 171-176, 2004.

3. Hirsch LR, Stafford RJ, Bankson JA, et al: Nanoshell-mediated near-infrared thermal therapy of tumors under magnetic resonance guidance. Proc Natl Acad Sci USA 100: 13549-13554, 2003.

4. Loo C, Lowery A, Halas N, West J and Drezek R: Immunotargeted nanoshells for integrated cancer imaging and therapy. Nano Lett 5: 709-711, 2005 .

5. Hainfeld JF, Dilmanian FA, Slatkin DN and Smilowitz HM: Radiotherapy enhancement with gold nanoparticles. J Pharm Pharmacol 60: 977-985, 2008.

6. Greish K: Enhanced permeability and retention of macromolecular drugs in solid tumors: a royal gate for targeted anticancer nanomedicines. J Drug Target 15: 457-464, 2007.

7. Sperling RA, Rivera Gil P, Zhang F, Zanella M and Parak WJ: Biological applications of gold nanoparticles. Chem Soc Rev 37: 1896-1908, 2008.

8. Chithrani BD, Ghazani AA and Chan WC: Determining the size and shape dependence of gold nanoparticle uptake into mammalian cells. Nano Lett 6: 662-668, 2006.

9. Chithrani BD and Chan WC: Elucidating the mechanism of cellular uptake and removal of protein-coated gold nanoparticles of different sizes and shapes. Nano Lett 7: 1542-1550, 2007.

10. Zhang X, Xing JZ, Chen J, et al: Enhanced radiation sensitivity in prostate cancer by gold-nanoparticles. Clin Invest Med 31: E160-E167, 2008.

11. Chang MY, Shiau AL, Chen YH, Chang CJ, Chen HH and Wu CL: Increased apoptotic potential and dose-enhancing effect of gold nanoparticles in combination with single-dose clinical electron beams on tumor-bearing mice. Cancer Sci 99: 1479-1484, 2008

12. Kong T, Zeng J, Wang X, et al: Enhancement of radiation cytotoxicity in breast-cancer cells by localized attachment of gold nanoparticles. Small 4: 1537-1543, 2008.

13. Hainfeld JF, Slatkin DN and Smilowitz HM: The use of gold nanoparticles to enhance radiotherapy in mice. Phys Med Biol 49: 309-315, 2004.

14. Song K, Kong B, Qu X, Li L and Yang Q: Phototoxicity of hemoporfin to ovarian cancer. Biochem Biophys Res Commun 337: 127-132, 2005.

15. Song K, Kong B, Li L, Yang Q, Wei Y and Qu X: Intraperitoneal photodynamic therapy for an ovarian cancer ascite model in Fischer 344 rat using hematoporphyrin monomethyl ether. Cancer Sci 98: 1959-1964, 2007.

16. Paciotti GF, Myer L, Weinreich D, et al: Colloidal gold: a novel nanoparticle vector for tumor directed drug delivery. Drug Deliv 11: 169-183, 2004.

17. Ghosh P, Han G, De M, Kim CK and Rotello VM: Gold nanoparticles in delivery applications. Adv Drug Deliv Rev 60: 1307-1315, 2008.

18. Han G, Ghosh P and Rotello VM: Functionalized gold nanoparticles for drug delivery. Nanomed 2: 113-123, 2007. 
19. Han G, Ghosh P and Rotello VM: Multi-functional gold nanoparticles for drug delivery. Adv Exp Med Biol 620: 48-56, 2007.

20. Rostgaard J and Qvortrup K: Electron microscopic demonstrations of filamentous molecular sieve plugs in capillary fenestrae. Microvasc Res 53: 1-13, 1997.

21. Yuan F, Dellian M, Fukumura D, et al: Vascular permeability in a human tumor xenograft: molecular size dependence and cutoff size. Cancer Res 55: 3752-3756, 1995.

22. Moghimi SM and Szebeni J: Stealth liposomes and long circulating nanoparticles: critical issues in pharmacokinetics, opsonization and protein-binding properties. Prog Lipid Res 42: 463-478, 2003.

23. Hatanaka M: Transport of sugars in tumor cell membranes. Biochem Bio Phys Acta 355: 77-104, 1974.

24. Flieri S, Mueckler MM, Usher P and Lodish HF: Elevated levels of glucose transportand transporter messenger RNA are induced by ras or src oncogenes. Science 235: 1492-1495, 1987.

25. Yamamoto T, Seino Y, Fukumoto H, et al: Over-expression of facilitative glucose transporter genes in human cancer. Biochem Biophys Res Commun 170: 223-230, 1990.

26. Fukuda H, Matsuzawa T, Abe Y, et al: Experimental study for cancer diagnosis with positron-labeled fluorinated glucose analogs: [18F]-2-fluoro-2-deoxy-D-mannose: a new tracer for cancer detection. Eur J Nucl Med 7: 294-297, 1982.

27. Herold DM, Das IJ, Stobbe CC, Iyer RV and Chapman JD: Gold microspheres: a selective technique for producing biologically effective dose enhancement. Int J Radiat Biol 76: 1357-1364, 2000.

28. Nel A, Xia T, Mädler L and Li N: Toxic potential of materials at the nano level. Science 311: 622-627, 2006.

29. Bhattacharjee SB and Das Gupta NN: Diffusion distance of the radicals produced by ionizing radiations in cells. Radiat Res 16 : 773-782, 1962

30. Sobolev AS, Jans DA and Rosenkranz AA: Targeted intracellular delivery of photosensitizers. Prog Biophys Mol Biol 73: 51-90, 2000

31. Li H, Jacque A, Wang F and Byrnes RW: Diffusion distances of known iron complexes in model systems. Free Radic Biol Med 26: 61-72, 1999.
32. Elgohary WG, Sidhu S, Krezoski SO, Petering DH and Byrnes RW: Protection of DNA in HL-60 cells from damage generated by hydroxyl radicals produced by reaction of $\mathrm{H}_{2} \mathrm{O}_{2}$ with cell iron by zinc-metallothionein. Chem Biol Interact 115 : 85-107, 1998

33. Rodriguez M, Dargemont C and Stutz F: Nuclear export of RNA. Biol Cell 96: 639-655, 2004.

34. Kahn BB: Dietary regulation of glucose transporter gene expression: tissue specific effects in adipose cells and muscle. $\mathrm{J}$ Nutr 124 (Suppl 8): S1289-S1295, 1994.

35. Mendez LE, Manci N, Cantuaria G, et al: Expression of glucose transporter-1 in cervical cancer and its precursors. Gynecol Oncol 86: 138-143, 2002.

36. Brown RS and Wahl RL: Overexpression of Glut-1 glucose transporter in human breast cancer. An immunohistochemical study. Cancer 72: 2979-2985, 1993.

37. Purrello F, Buscema M and Vetri M: Glucose regulates both glucose transport and the glucose transporter gene expression in a hamster-derived pancreatic beta-cell line (HIT). Diabetologia 34: 366-369, 1991

38. De Jong WH and Borm PJ: Drug delivery and nanoparticles: applications and hazards. Int J Nanomed 3: 133-149, 2008.

39. Lai MK, Chang CY, Lien YW and Tsiang RC: Application of gold nanoparticles to microencapsulation of thioridazine. J Control Release 111: 352-361, 2006.

40. Kubota H, Suzuki T, Lu J, et al: Increased expression of GRP94 protein is associated with decreased sensitivity to X-rays in cervical cancer cell lines. Int J Radiat Biol 81: 701-709, 2005.

41. Kunkel M, Moergel M, Stockinger M, et al: Overexpression of GLUT-1 is associated with resistance to radiotherapy and adverse prognosis in squamous cell carcinoma of the oral cavity. Oral Oncol 43: 796-803, 2007.

42. Wyld L, Reed MW and Brown NJ: Differential cell death response to photodynamic therapy is dependent on dose and cell type. Br J Cancer 84: 1384-1386, 2001.

43. Ling CC, Guo M, Chen CH and Deloherey T: Radiation-induced apoptosis: effects of cell age and dose fractionation. Cancer Res 55: 5207-5212, 1995. 